\title{
O TRÁGico, A BELEZA E O SENTIDO: UMA ANÁLISE LOGOTERAPÊUTICA DO FILME “MELANCOLIA"*
}

\author{
Marcos Antônio Dias Júnior**
}

\begin{abstract}
RESUMO
Este trabalho se propõe a uma análise do filme "Melancolia" (2011), dirigido por Lars Von Trier, a partir dos conceitos da Logoterapia e Análise Existencial em um breve recorte sobre o trágico e a beleza. 0 objetivo é tentar entender a relação entre sentido da vida e beleza mesmo na tragédia a partir dos conceitos da Logoterapia. 0 método é o qualitativo estudo de caso e a metodologia analise de conteúdo. A análise do filme permitiu identificar como os personagens selecionados tomam decisões diferentes diante do trágico, porem só um deles encontra sentido e beleza na vida, realizando valores, percebendo que vale a pena viver até o último instante, mesmo diante da morte, do trágico. Palavras-chave: Logoterapia. Trágico, Beleza. Sentido da vida. Filme.
\end{abstract}

\section{THE TRAGIC, BEAUTY AND MEANING: A LOGOTHERAPEUTIC ANALYSIS OF THE MOVIE "MELANCHOLIA"}

\begin{abstract}
This work proposes an analysis of the film "Melancolia" (2011), directed by Lars Von Trier, based on the concepts of Logotherapy and Existential Analysis in a brief cut on the tragic and the beauty. The goal is to try to understand the relationship between the
\end{abstract}

* Trabalho de conclusão da especialização em Logoterapia e Analise Existencial, pelo Núcleo Mineiro de Logoterapia.

** Psicólogo, especialista em Logoterapia e Analise Existencial, pelo Núcleo Mineiro de Logoterapia 
meaning of life and beauty even in the tragedy from the concepts of Logotherapy. The method is the qualitative and the content analysis methodology. The analysis of the film allowed to identify how the selected characters make different decisions in the face of the tragic, but only one of them finds meaning and beauty in life, realizing values, realizing that it is worth living until the last moment, even in the face of death, of the tragic.

Keywords: Logotherapy, Tragedy, Beauty, Sense of life, Movie.

\section{INTRODUÇÃo}

"No dia seguinte ninguém morreu" (SARAMAGO, 2005, p. 11), afirma José Saramago no início do seu livro Intermitências da morte. A "Morte", personagem da estória, decide não "levar" mais ninguém daquele país. 0 que parece ser um paraíso de vida eterna se torna um verdadeiro caos no desenrolar da narrativa. E enquanto isso a "Morte" passa por um processo de humanização e se apaixona por um homem da Terra. Por mais que a morte seja trágica essa obra de arte de Saramago (2005) mostra que a vida pode ser mais trágica ainda na ausência da morte.

Atualmente o ser humano procura uma vida como a da estória citada por Saramago (2005). Grande parte da humanidade tem o interesse em viver sem finitude e assim fugir da morte, por medo, independentemente das consequências a que isso possa levar. É uma corrida, não em direção ao que faz sentido ou é belo na vida, mas correndo em fuga do trágico em todas as suas manifestações.

Cabe ressaltar que aqui se entende por trágico aquilo que todo ser humano um dia vai se deparar em sua vida como "culpa, morte e sofrimento" (FRANKL, 2019a). A culpa, a morte e o sofrimento inevitável são situações que não se pode escapar em nossa condição humana e devem ser enfrentadas, porém não é o que se vê acontecendo no mundo contemporâneo. De forma alguma se pretende dizer, assim como Frankl (2019a), "que o sofrimento seja necessário, pelo contrário, o que afirmo é que o sentido é possível apesar do sofrimento, para não dizer por intermédio de um sofrimento" (FRANKL, 2019a, p. 96). Para o autor, diante de um sofrimento inevitável, cabe à pessoa descobrir o sentido da vida. Quando o sofrimento pode ser evitado deve-se eliminá-lo. 
Para Aquino et al. (2010b), na Idade Média a morte era um tema familiar, os mortos eram velados dentro de casa, logo a morte estava quase sempre presente. No século XVIII a morte era até mesmo tema das peças teatro e exaltada de forma diferente ao período anterior. No século atual a morte se tornou algo a ser combatido de forma veemente, ela é vista como inimiga, e morrer é visto como fracasso.

Mas ao combater a morte ignorando-a como se ela não existisse, o que parece ser uma vitória na contemporaneidade, está paradoxalmente desencadeando o que sempre assolou o homem diante da morte: medo e angústia. Aquino et al. (2010a) afirma que essa negação leva o ser humano a submeter-se "a um ritmo acelerado de vida, caracterizado pela sua alta produtividade no âmbito pessoal, social, econômico. Consequentemente, quando toma consciência da morte, isso poderá desencadear o medo e angústia perante essa finitude." (AQUINO et al., 2010a, p. 236).

Com efeito, o medo e a angústia levam a um estado que tem afetado tanto as relações, como as obras artísticas atuais, que parecem estar contaminadas por essa "humanidade que não morre" e que cultua uma beleza sem essência. Sobre isso Roger Scruton (2013), filósofo contemporâneo, afirma que a "arte mais recente, por sua vez, cultiva uma postura transgressora, igualando a feiura daquilo que retrata com uma feiura própria. A beleza é rebaixada a algo demasiadamente doce e escapista, distanciando-se demais das realidades para merecer uma atenção desenganada." (SCRUTON, 2013, p. 178). A arte de hoje é a arte que se olha, mas não diz nada para quem a vê ou até mesmo sobre a realidade em que ela está inserida. Sendo assim não tem a menor capacidade de prender atenção de quem está diante dela, de competir com o excesso de informações das mídias, da internet. A arte que pode refletir a realidade que o homem esconde de si mesmo tem refletido apenas fantasias. Para o autor o que temos hoje não é arte e sim

objetos fantasiosos, visto que as imagens realistas da fotografia, do cinema e da TV oferecem uma satisfação substituta a nossos desejos proibidos, legitimando-os, portanto, dessa forma. Um desejo fantasioso não busca nem uma descrição literária, nem a pintura delicada de um objeto, e sim um simulacro - uma imagem em que todos os véus da hesitação foram rasgados. [...] A fantasia ideal é perfeitamente re- 
alizada e perfeitamente irreal - um objeto imaginário que nada deixa a cargo da imaginação. As propagandas comercializam tais objetos, os quais pairam no pano de fundo da vida moderna e, a todo o momento, nos instigam a realizar nossos sonhos em vez de buscar as realidades. (SCRUTON, 2013, p. 115).

Indo em outra direção, a Logoterapia e Análise Existencial não compreende o homem como aquele que busca somente equilíbrio e felicidade. Ou que vive à mercê da vontade do prazer, como, de acordo com o entendimento de Frankl (2019a), defendia Sigmund Freud em sua teoria psicanalítica, ou da vontade de poder, como, segundo o autor também, afirma Alfred Adler em sua teoria da psicologia individual. A teoria de Viktor Frankl (2019a) "fala de uma vontade de sentido e a considera [...] como algo primário" (FRANKL, 2019a, p. 41), que move o ser humano em direção ao sentido. 0 sentido é o que em cada situação da vida tem um valor inestimado. Segundo Frankl (2009) "a Logoterapia, de fato, confronta o paciente com o sentido de sua vida e o reorienta para o mesmo." (FRANKL, 2009, p. 124). 0 autor entende que o homem é chamado a encontrar sentido, pela via da realização de valores e que é responsável para tal.

Frankl (2009) apresenta sua tríade de valores: de criação, de vivência e de atitude. Para o autor esses três valores são as únicas vias para o encontro de sentido. Para o autor os valores criativos são aqueles em que o homem se dedica a criar algo, um trabalho, podendo assim oferecer isso ao mundo. Já os valores vivenciais são aqueles em que pode experienciar ou aproveitar algo que recebe do mundo, como amar alguém, contemplar uma arte ou até mesmo a beleza da natureza. Já o terceiro valor, de atitude, revela a capacidade que o homem tem, diante de uma situação de sofrimento que não pode ser mudada, de mudar a si mesmo.

As perguntas que movem esse trabalho são: é possível encontrar sentido e beleza em um contexto de morte e sofrimento? Qual a relação desses elementos na tragédia do filme "Melancolia"? Através da análise do filme "Melancolia" o objetivo desse trabalho é entender a relação entre sentido da vida e beleza em um contexto trágico a partir de alguns conceitos da Logoterapia. 
A escolha pelo método qualitativo se deu pelo fato de o trabalho corresponder ao que segundo Bardin (2011) é a "elaboração das deduções específicas sobre um acontecimento" (BARDIN, 2011, p. 145). Sendo o filme esse acontecimento será levado em consideração seu tema e personagens para o levantamento de conclusões, e não a frequência desses ou mesmo de palavras no decorrer da obra, como aborda Bardin (2011).

Metodologicamente o presente trabalho usa a análise de conteúdo, que segundo Bardin (2011) é uma codificação, interpretação, dos dados estudados. Para isso será citado os "personagens". Para o autor filmes podem ser analisados por seus personagens e com isso temos a possibilidade de fazer questionamentos como: qual papel ele esta desempenhando? Com qual finalidade? Qual a situação enfrentada?

Serão apresentados alguns conceitos da teoria de Viktor Frankl, como: sentido da vida, tríade de valores, tríade trágica, melancolia, vazio existencial, responsabilidade, sentido último. Para melhor entendimento desses conceitos, será feita uma análise de recortes do filme "Melancolia" (2011), de Lars Von Trier. Para o estudo de caso serão escolhidos apenas dois personagens do filme: Justine e John. Através das histórias deles e de suas escolhas ante a tragédia buscaremos correlacionar o tema da beleza e o sentido da vida na perspectiva logoterapêutica.

\section{ATravessando uma TRAGÉdia melancólica}

Melancolia (título original Melancholia) é um drama de ficção científica, dirigido por Lars Von Trier, lançado em 2011. O filme conta a história da noiva Justine (Kirsten Dunst), que está em plena festa de casamento. Festa essa luxuosa, feita pela sua irmã Claire (Charlotte Gainsbourg) e seu cunhado John (Kiefer Sutherland). Concomitante a este contexto o planeta Terra está prestes a colidir com outro planeta chamado Melancolia, o que levará a sua destruição completa.

O filme começa com quadros, ou poderíamos dizer "telas", de cenas que aconteceriam no filme, em câmera lenta, quase sem movimento, ao som da trágica música "Tristão e Isolda", que é a trilha sonora principal do filme. As telas são relances do que acontecerá na 
história e ao mesmo tempo nos deparamos com belas representações do estado emocional de Justine. Outra coisa que é surpreendente nessa etapa do filme são as belas paisagens que envolvem os personagens, fotografias belíssimas da arquitetura, da natureza e do espaço, já mostrando a colisão do planeta Terra com o planeta "Melancolia". Ou seja, no início desse filme já sabemos o seu final: a morte é evidente. A partir disso destaca-se dois personagens que tem fins distintos: Justine e John.

A seguir serão citadas algumas cenas e as falas dos personagens escolhidos, referenciadas pela hora, minuto e os segundos em que acontecem no desenrolar da estória.

37min57s - John, marido de Claire e pai de Leo tem uma visão totalmente científica, reducionista e pragmática da vida. Na cena, com os sinais da depressão/melancolia de Justine vindo à tona em plena festa de casamento, John afirma que ela deveria estar feliz e questiona a ela pela segunda vez se referindo ao dinheiro dele gasto na festa: "tem alguma ideia de quanto me custou essa festa?".

1h24min - No decorrer do filme John aparece com outra postura, mais descontraído e bem confiante com relação à passagem, como ele afirma "inofensiva" do planeta "Melancolia" pela órbita da Terra. Bem-informado com relação ao acontecimento, ele tem equipamentos para analisar e observar a passagem do planeta, como alguém que está sempre observando as estrelas ou a lua, e fazendo cálculos a respeito. Ele aparece cuidando de toda a família e brincando com seu filho.

1h29min - John vê Claire guardando alguns remédios que tinha acabado de comprar e a questiona se ela quer matar a todos com aqueles remédios. Quando o planeta começa a passar por eles sem causar nenhum dano à Terra, ao não ser uma queda de energia elétrica, John faz um brinde a vida.

1h41 min - John está inquieto e preocupado, olhando para o "Melancolia", indo para lá e pra cá, fazendo cálculos. Logo em seguida ele sai de cena e sua mulher percebe que o planeta não está se distanciando da Terra e sim vindo ao seu encontro. Claire procura John e não o encontra, então percebe que os remédios que ela havia comprado sumiram. 
1h46min - John é encontrado morto por Claire no estábulo que eles tinham. Na sua boca escorria um líquido branco o que indicava uma overdose com os remédios de sua esposa, que haviam sumido.

Justine parece estar na mesma direção do destino de John, mas trilha um caminho diferente do dele, consequentemente com outro desfecho:

12 min12seg - Justine começa o filme radiante, aparentemente muito feliz com seu casamento, demonstra uma sensibilidade aos fenômenos da natureza e na sequência carinho por seu cavalo que ficava no estabulo. Ela vê uma estrela vermelha no céu, e John fica surpreso por ela ter visto e afirma que é difícil encontrá-la.

$42 \mathrm{~min}$ - Justine entra em um escritório/biblioteca e encontra seu noivo e sua irmã conversando e decepcionados com tudo que ela vem demonstrando. Michael, seu noivo, se retira, e Justine começa a pedir desculpas para Claire e dizer que está se esforçando e "sorrindo, sorrindo e sorrindo" durante toda a noite. Sua irmã se irrita e sai da sala dizendo que ela está mentindo para todos e a deixa sozinha ali. De repente, sozinha, Justine repara que tem livros abertos com páginas que mostram obras de arte com formas geométricas, abstratas, e que são quadros do pintor Kazimir Malevich. Então ela se levanta descontente, com um semblante de raiva e choroso, e começa a abrir os livros, de forma agressiva, em outras páginas. Ela rapidamente procura nos livros as obras que quer colocar a mostra e então abre os livros nestas páginas deixando à vista as obras de arte que escolheu: o Caçador na neve, de Brügel; Millais com sua Ofélia; Davi com a cabeça de Golias, de Caravaggio; Terra de cocanha, de Brügel; Cervo Bramindo, de Carl Fredrik Hill.

1h09min - no segundo ato do filme, toda a depressão de Justine vem à tona e Leo pergunta novamente sobre a caverna para ela, mas ela está totalmente depressiva, com semblante totalmente abatido, não conseguindo ficar de pé sozinha, aparentemente desarrumada para a viagem que fez, e não consegue responder ao sobrinho.

1h13min - Para Justine a vida agora aparenta não ter mais cor nem gosto, como a sua comida predileta no jantar que ela afirma estar com gosto de cinza. 
1h23seg - Nesta cena, onde o planeta "Melancolia" está bem mais evidente nos céus, a protagonista vai até a floresta e fica nua diante do planeta, como se estivesse se banhando em sua luz.

1h31min - Justine demonstra ainda certo pessimismo com relação a tudo, afirmando a sua irmã que não há problema em a terra ser destruída, pois ninguém sentirá a sua falta por ela ser má.

1h58min - Justine está com seu sobrinho que está com um semblante triste e preocupado. Ela pede para ele não ter medo, então Leo retoma as palavras de seu pai dizendo que se o "Melancolia" colidir com a terra não tem onde se esconder. Justine diz a Leo: "Se o seu pai disse isso ele esqueceu uma coisa: ele se esqueceu da caverna mágica". Então Leo, acreditando nessa solução, pergunta a ela se qualquer um pode construir essa caverna e ela responde: "A tia Steelbreaker pode". É assim que Leo chama a tia desde a primeira cena com ela, porém ela não assumiu esse nome até esse momento.

1h59min52seg - Justine está com Leo no meio da mata pegando gravetos para construir a "caverna”, ela está com o que parece ser o canivete que Leo deu a ela no início do filme, eles já estão ficando ofegantes, pois quanto mais o "Melancolia" se aproxima, mais a terra vai perdendo oxigênio, e a dificuldade de respirar aumenta. Ela faz um carinho nos cabelos de Leo.

2h01min39seg - Justine, já dentro da "caverna mágica”, junto com Claire e Leo, pede a seu sobrinho para lhe dar mão e então o planeta "Melancolia" colide com a terra.

\section{A beleza e a tragédia na ARTE}

A beleza que é almejada por muitos não tem sido encontrada hoje em dia, mas não por ela ter deixado de existir, e sim pelo fato de o ser humano estar perdido em si mesmo. A beleza é a passagem, a ponte, que ajuda o ser humano a sair de si mesmo em direção à vida, mesmo que ela tenha aspectos trágicos. Já a arte seria o local de morada da beleza e ao mesmo tempo o veículo que o ser humano pode usar para atravessar essa ponte em direção a um outro, aquele que não é o si mesmo, que é diferente dele mesmo. Mesmo que esteja em uma situação rude e dolorosa, ele pode ainda ver beleza ou criar algo 
belo a partir daquela situação trágica. A beleza aparece naturalmente na relação com outro, quando o ser humano se abre as possibilidades, mesmo sendo diante do que é trágico.

Não só um acontecimento trágico pode ser belo como também a beleza pode ser encontrada no "entre", como uma ponte que liga duas extremidades. Segundo Han (2019) o "belo está localizado entre o desastre e a depressão, entre o horrível e o morto-vivo, entre o adentrar do outro e o petrificar-se no igual" (HAN, 2019, p. 66).

Entretanto a beleza além de ser algo a ser encontrado é algo que faz encontrar, achar o caminho. Ela leva, por exemplo, a uma pessoa que se perdeu em si mesma, que está sem perspectiva, sem opções, a voltar ao caminho das possibilidades. Para Scruton (2013) os "amantes da beleza voltam sua atenção para fora, buscando um sentido e uma ordem que deem razão a suas vidas." (SCRUTON, 2013, p. 197). Já para Han (2019), a "salvação do belo é a salvação da vinculação" (HAN, 2019, p. 113).

Ter opções é ter a possibilidade de fazer escolhas, e para escolher o ser humano é livre. Através da beleza essa liberdade se potencializa. Seja nos arranjos do dia a dia, bem como em uma obra de arte, pode-se ter mais opções na vida. Para Scruton (2013) "[...] certo elemento de liberdade é incorporado à busca da beleza, seja a beleza mínima dos arranjos cotidianos, seja a beleza superior da arte." (SCRUTON, 2013, p. 153).

Em que, na qual está o trágico ali também há beleza. As verdadeiras obras de arte não são aquelas que ignoram o trágico, que são feitas apenas dos aspectos prazerosos e felizes da vida. Tentar excluir o trágico pode levar o ser humano a cair no "inferno do igual", sem mudanças e sem perspectivas, repetindo apenas a mesma coisa em sua vida e em tudo o que faz. Segundo Scruton (2013)

em qualquer imagem de um dos grandes pintores paisagísticos - Poussin, Guardi, Turner, Corot, Cézanne - você verá essa ideia de beleza celebrada e fixada em imagens. Tais artistas não fecham os olhos nem para o sofrimento, nem para a vastidão e periculosidade desse universo, que só tem por nós ocupada uma ínfima extensão. Os pintores de paisagens nos revelam a morte e a decadência no coração mesmo das coisas: a luz que incide sobre suas colinas é uma luz moribunda; as paredes de 
suas casas têm remendos e se esfarelam, como o estuque das aldeias de Guardi. No entanto, essas imagens também apontam tanto para a alegria que jaz incipiente na decadência como para a eternidade que se encontra implícita no que é transitório (SCRUTON, 2013, p. 186).

\section{BUSCANDO SENTIDO NA VIDA}

Viktor Frankl dedica-se ao sentido da vida e apresenta isso em sua teoria. Para ele não só há uma possibilidade de encontrar sentido através da realização de valores, mas que também através dessa realização pode o homem enfrentar o trágico da vida inevitável, pois a pessoa é livre para mudar a si mesma diante de situações imutáveis e pode sempre escolher de forma responsável, valorosa e bela.

O sentido aparece para cada pessoa de forma única, ele está presente na concretude da vida, nas relações interpessoais. Para Frankl (2009) o "sentido é exclusivo e específico, uma vez que precisa e pode ser cumprido somente por aquela determinada pessoa" (FRANKL, 2009, p. 124) em uma determinada situação. Ele pode ser subjetivo e relativo, mas não como criação do ser humano. Frankl (2019b) explica que: "o sentido é subjetivo na medida em que não há um sentido para todos, mas sim um sentido para cada um dos outros; entretanto, no caso concreto de que se tratar, o sentido não pode ser puramente subjetivo" (FRANKL, 2019b, p. 105). Nos casos concretos o sentido está ali, objetivamente, com a possibilidade de ser descoberto. Já com relação ao sentido ser relativo o autor afirma que ele:

está numa determinada relação com a pessoa, - e com a situação em que precisamente essa pessoa se realiza e se insere. Sob este prisma, é claro que o sentido de uma situação é realmente relativo; é-o, assim, em relação a uma situação tomada, no caso concreto, como irrepetível e única (FRANKL, 2019b, p. 106).

Segundo Frankl (2019b) a consciência é responsável por perceber a forma como o sentido se configura e como ele se apresenta em cada situação. Ela mostra como captar o sentido e identifica os valores que requerem realização. A consciência do homem aponta para o sentido da vida. E é através da realização de valores, sejam eles criativos, de vivência e ou de atitude, que se percorre a via até o sentido. 
É tamanha a relevância do sentido que o ser humano pode viver uma vida inteira sempre com dignidade. Segundo o Frankl (2009), até no momento de sua morte, o homem pode realizar o que faz sentido na vida, vivenciar seus ideais e valores até em seus últimos instantes.

Tem um sentido que ultrapassa a capacidade finita do ser humano de entendimento que é o sentido último. Também conhecido como supra-sentido, está para além do que é logico, de uma forma mais profunda ele é o sentido que dá sentido a todos os outros sentidos na vida. Para Frankl (2009) a vida tem um sentido incondicional e o

que se requer da pessoa não é aquilo que alguns filósofos existenciais ensinam, ou seja, suportar a falta de sentido da vida; o que se propõe é, antes, suportar a incapacidade de captar em termos racionais o fato, de que a vida tem um sentido incondicional. 0 logos é mais profundo que a lógica (FRANKL, 2009, p. 142).

Na vida humana também se passa pelo trágico. Mesmo diante do sofrimento fatal, da culpa que não se pode contornar e da morte que não se pode escapar, ainda assim o ser humano, respectivamente nessa ordem, pode se realizar, mudar e ser responsável. Com tudo, para Frankl (2019b),

não há na vida nenhuma situação que realmente careça de sentido. Quer dizer: as faces aparentemente negativas da existência humana, especialmente aquela tríade trágica em que se entrelaça a dor, a culpa e a morte, sempre se podem converter em algo de positivo, numa realização, se as sabemos enfrentar com comportamento e atitudes corretos (FRANKL, 2019b, p. 397).

Existe um fim para a vida e saber desse fim é o que nos leva a cumprir o nosso dever o quanto antes. "A finitude, a temporalidade, não é apenas, por conseguinte, uma nota essencial da vida humana; é também constitutiva do seu sentido." (FRANKL, 2019b, p. 145). Enquanto estamos vivos só temos essa única chance para ser responsáveis e é aí que entendemos que o "sentido da existência humana funda-se no seu caráter irreversível.” (FRANKL, 2019b, p. 145). 
Segundo Frankl (2019b) a morte não precisa ser paralisante, ela não precisa ser apenas fonte de medo e angústia, levando o homem a não fazer nada diante da vida, já que um dia ele vai morrer. Pelo contrário, ela impele o homem a pensar sobre a vida e fazer o quanto antes o que é importante, pois se

fôssemos imortais, poderíamos, com razão, adiar cada uma das nossas ações até o infinito; nunca teria a menor importância o realiza-las agora, neste momento preciso, podendo muito bem realiza-se amanhã ou depois de amanhã, ou daqui a um ano ou dez. Em compensação, tendo em vista a morte como fronteira infranqueável do nosso futuro e limite das nossas possibilidade, vemo-nos obrigados a aproveitar o tempo de vida que dispomos e a não deixar passar em vão as ocasiões irrepetíveis que se nos oferecem, ocasiões essas cuja a soma "finita" representa precisamente a vida toda (FRANKL, 2019b, p. 145).

A transitoriedade da vida nos leva diretamente a pensar na responsabilidade. Para Frankl (2009) a consciência das possibilidades transitórias da vida nos remete a possibilidade de escolha. Quando nascemos não escolhemos, não somos questionados se queremos vir ao mundo, mas durante a vida somos impelidos a escolher sempre. A responsabilidade é um lado da moeda para Frankl (2019a), o seu outro lado seria a liberdade. 0 ser humano é livre para escolher desperdiçar a sua vida ou realiza-la com sentido, por isso deve escolher com responsabilidade.

0 autor entende por responsabilidade a capacidade do homem de responde ao chamado da vida para realização de valores. Segundo Frankl (2009) não é o ser humano que tem que indagar a vida e sim essa que o questiona. 0 "viver não significa outra coisa que arcar com a responsabilidade de responder adequadamente às perguntas da vida, pelo cumprimento das tarefas colocadas pela vida a cada indivíduo, pelo cumprimento da exigência do momento" (FRANKL, 2009, p. 102). Frankl (2009) questiona se temos que dizer sim a vida apesar de tudo de trágico que acontece nela. Dizer "sim à vida" para o autor "pressupõe que a vida potencialmente tem um sentido em quaisquer circunstâncias, mesmo nas mais miseráveis" (FRANKL, 2009, p. 161). 
Todas as vezes que realizamos valores estamos diante da possibilidade de encontrar sentido. Uma das formas que os valores podem ser realizados é, segundo Frankl (2019a), "sofrendo, sofrendo a existência, o destino" (FRANKL, 2019a, p. 296), a esses chamamos valores de atitude. A pessoa pode não ter condições de realizar valores vivencias ou de criação, mas ainda assim resta o valor de atitude, o valor que dá a ela a possibilidade de mudar a si mesma mesmo diante de situações dolorosas imutáveis. Para o autor:

Aos valores que se realizam pelo sofrimento do mundo e do destino, o próprio fato de haver na pessoa um retraimento diante da realização dos valores criadores e vivenciais, dá uma oportunidade de desdobramento pela adoção de uma atitude adequada. 0 retraimento necessário e a limitação das possibilidades de valor acabam significando um avanço no rumo do mais alto sentido e das mais elevadas possibilidades de valor que o sofrimento contém em si. (FRANKL, 2019a, p. 296).

O sofrimento faz o homem sentir de certa forma como ele não deve agir no mundo. 0 sofrimento, a culpa e a morte fazem parte da vida. "Nenhum desses elementos se pode separar da vida sem lhe destruir o sentido. Privar a vida da necessidade da morte, do destino e do sofrimento, seria como tirar-lhe a configuração, a forma" (FRANKL, 2019b, p. 198). Segundo o autor quando possível, diante do sofrimento, deve-se configurá-lo; enquanto houver possibilidade deve-se mudar a si mesmo.

Diante de sua livre possibilidade de escolha o ser humano pode errar, seja por escolher sem responsabilidade, ou sem prezar pela dignidade, ou se omitindo, e com isso se torna culpado em sua ação. A culpa tem por característica fazer do homem "ser-responsável” pelo que fez, mas sem o "ser-livre" do mesmo. A pessoa que é culpada pode aguentar o peso da responsabilidade do seu ato, mas não poderá abrir mão do que fez, apagar o ato. Contudo segundo Frankl (2009) o homem é livre para mudar a si mesmo diante de sua culpa, ele é responsável por ela e por sua mudança. Afirma o autor que “'Ser-homem' que dizer sempre decidir o que devo fazer de mim mesmo, e isto, por seu turno, significa assumir a responsabilidade do que fiz de mim mesmo." (FRANKL, 2019a, p. 98). 
Um dos aspectos negativos da vida para Logoterapia é o sentimento de falta de sentido, que acontece quando o homem acredita que a vida não tem um sentido. Segundo Frankl (2009) o sentimento de falta de sentido não é causado por uma patologia, muito menos é uma patologia em si, mas sim é algo próprio do ser humano, da existencial humana. Porém o sentimento de falta de sentido tem potencial patogênico, ele pode levar a pessoa a adoecer, a deprimir-se, ser agressiva consigo ou com o outro, ou até mesmo depender de drogas para tentar suportar a realidade (FRANKL, 2009).

Pensamos na síndrome neurótica de massa tão presente na jovem geração: há ampla evidência empírica de que as três facetas desta síndrome - depressão, agressão, dependência de drogas - são devidas ao que se chama em logoterapia "o vazio existencial", um sentimento de vacuidade e de falta de sentido. (FRANKL, 2009, p. 165).

Vazio existencial é quando o homem tem a falsa sensação de que a sua vida não tem significado e ao mesmo tempo não consegue ter consciência de que essa tem um sentido pela qual vale a pena continuar. Para Frankl (2019a) o ser humano, em sua gênese, em sua essência, tem como primordial o "preenchimento do sentido e a efetivação do valor - em síntese, a realização no plano existencial (a nosso ver, 'existencial' tem a ver não somente com existência, mas com o sentido de existência)" (FRANKL, 2019a, p. 42).

Devido, por exemplo, à falta de emprego, ou de alguém para amar, ou de não enxergar perspectivas de mudança diante de uma situação fatal, o ser humano pode acreditar na falsa ideia de que a vida não tem sentido. Com essa sensação de vazio uma pessoa pode se deprimir e deprimida pode atentar contra a própria vida. Para Frankl (2019a) "o suicídio, obedece em geral a uma depressão, e esta pode ter sua origem [...] em um sentimento de ausência de sentido." (FRANKL, 2019a, p. 90). Para o autor não é toda a depressão que é causada por um sentimento de falta de sentido e nem é todo suicídio, que por vezes é causado pela depressão, é resultante do vazio existencial. Mas Frankl (2009) entende que mesmo que o deprimir-se e o retirar a própria vida não tenha acontecido por causa do vazio, "é bem possível que o impulso de tirar 
a vida tivesse sido superado se a pessoa tivesse estado consciente de algum sentido e propósito pelos quais valesse a pena viver" (FRANKL, 2009, p. 165).

Diferente da depressão causada pelo sentimento de falta de sentido, do vazio existencial, há também a depressão endógena. Segundo Frankl (2019b) a depressão endógena é de origem biológica. 0 autor procura, pela ótica da Análise Existencial, compreender a depressão endógena como um "modus da existência" que tem como sintoma característico a angústia. Já no campo biológico ela é caracterizada por uma baixa vital.

De acordo com Frankl (2019b) a baixa vital será vista como uma "sensação de insuficiência" no âmbito fisiológico. No âmbito do modo ser-homem essa baixa vital é vivida como incapacidade para "cumprir uma missão" ante a vida (Frankl, 2019b). A Logoterapia propõe através do valor de atitude que a pessoa pode mudar a si mesma, exercendo sua liberdade, tomando uma posição diante do seu adoecer. Por exemplo, uma pessoa melancólica, em tratamento logoterapêutico, tem a possibilidade de uma mudança de atitude, decidindo vivenciar o que faz sentido em sua vida, superando seu desinteresse pela mesma, realizando aquelas tarefas que pedem cumprimento. Frankl (2019b) descreve a dinâmica do fenômeno da melancolia que é:

Está é predominantemente angustia de morte e da consciência. Toda via, só poderemos compreender o sentimento de angustia do melancólico e a sua vivência de culpa se os concebermos como um modo do ser-homem, como uma modalidade da existência humana. 0 certo é que a mera baixa vital não nos explica nada - e afinal como se sabe, nunca foi explicado até hoje essa baixa vital. (FRANKL, 2019b, p. 341).

Frankl (2019b) acredita que quem sofre de depressão endógena, assim como outras patologias orgânicas semelhantes, precisa aceitar a sua doença. Com essa aceitação surge para pessoa a possibilidade real de realizar valores. Para o autor o "resto de liberdade que continua presente na psicose, na atitude livre do doente em face dela, possibilita-lhe, em cada caso, a realização de valores de atitude" (FRANKL, 2019b, p. 340). 


\section{Buscando SENTIDo NO TRÁgico E ENCONTRANDO BELEZA}

Frankl (2019b) afirma que "arte foi uma vez definida como unidade na pluralidade." (FRANKL, 2019b, p. 20). Mesmo diante de diversos gêneros artísticos (música, dança, pintura, cinema...) a arte sempre é arte, complexa, porem única em suas várias manifestações. Para o autor o homem é visto como uma perspectiva tridimensional, biológica, psíquica e nooetica, no qual o nooetico faz referência às capacidades humanas da criatividade, liberdade, responsabilidade, entre outros. A beleza também se recusa a ter uma definição simples já que por ser diversa em sua manifestação é única e inconfundível. 0 que vai nos permitir a compreensão da definição da arte, do homem e da beleza, bem como a relação entre eles, é justamente essa abertura aos aspectos múltiplos: a arte é mais do que a obra em si, que segue critérios técnicos, sem vida, ela é beleza, tragédia, revelação, inspiração, uma tela onde podemos ver o mundo; o homem é mais do que seu psíquico e seu biológico, ele é também uma dimensão livre e criativa; a beleza não é mero sincronismo estético, ela é um valor próximo à verdade e a bondade, uma ponte, mas também um contorno. 0 filme "Melancolia" enquanto arte é uma ponte que nos leva diante da beleza na tragédia e seus personagens enquanto representação de ser-humanos nos mostram possíveis escolhas a serem feitas diante da morte.

A história, apesar de trágica, nos mostra que o ser humano pode ser influenciado pela arte e se ver refletido nela, bem como, também, tem a possibilidade de escolher pelo desistir, ou pela realização de valores vivenciais, criativos e atitudinais até o último instante possível. Com efeito, embora mesmo que se trate de um só momento a vida pode ser rica em valores e "pela grandeza de um momento já se pode medir a grandeza de uma vida" (FRANKL, 2019b, p. 113).

0 trágico não é fechamento dessas multiplicidades únicas, o fim das possibilidades de realizar valores, ele compõe esses múltiplos únicos, e não deixa de ter seus aspectos e ainda sim ser único é valioso. E é assim também com a vida. "Ora, o que nos permite compreender o valioso da vida, independentemente da estreiteza das suas circunstâncias, é precisamente a apreensão de toda a riqueza do reino dos 
valores." (FRANKL, 2019b, p. 112). Como vimos pelo preludio do filme à tragédia é evidente, mas não se encerra para a vida suas possibilidades de sentido. Imagens belas, representando vivencias possíveis dos personagens, que demonstram como o ser humano em suas relações ou junto a natureza podem ou não realizar valores.

0 autor afirma também que a forma "de encontrar um significado na vida é experimentando algo - como a bondade, a verdade e a beleza, experimentando a natureza e a cultura ou, ainda, experimentando outro ser humano em sua originalidade própria - amando-o." (FRANKL, 2009, p. 135).

Seja criando, ou experenciando, uma única arte pode afetar diversas pessoas diferentes. Ela é requerida pelo homem, pois através dela ele pode lembrar ou se esquecer de si mesmo, mas sem se encerrar em si. Requer um movimento para fora de si, mesmo que do lado de fora seja assustador, porém esse assustador não se compara com o "inferno" da vivencia de encerrar em si sem enxergar as possibilidades de mudanças.

No filme, (aos $42 \mathrm{~min}$ ) Claire explicita a mentira de sua irmã e por sua vez a arte revela a verdade de Justine. Ela através das obras de arte, nos dá uma pista de como realmente está se sentindo e vivendo: em uma terra congelada (e no caso dela pela vivencia da melancolia) como na dos "Caçadores na neve"; em uma tragédia como a de "Ofélia"; precisando arrancar a "cabeça do gigante" que a atormenta; sem limites, como na "Terra de Cocanha", toda sua energia se esvai; e por fim, ela precisa de voz, de gritar, bramir, mesmo estando sozinha, como o "cervo". Para Scruton (2019) as escolhas das obras de arte podem revelar muito sobre quem as escolhe. Para o autor as obras artísticas "nos interessam, em parte, porque representam coisas, contam histórias, expressam ideias e emoções e comunicam significados almejados conscientemente." (SCRUTON, 2019, p. 77). Frankl (2009) nos conta que, mesmo em lugar como em um campo de concentração nazista, rodeado pela morte e por pessoas sofrendo houve arte:

Arte no campo de concentração será possível isso? Claro, depende do que se chama de arte. Vale dizer que vez por outra havia inclusive teatro improvisado. [...] Apresentam-se algumas canções e recitam-se poemas, contam-se ou apresentam-se cenas cômicas, ou mesmo sátiras 
alusivas à vida no campo de concentração, tudo para ajudar a esquecer. E realmente ajuda! (FRANKL, 2009, p. 59).

Como Frankl (2019b) afirma, a melancolia leva a uma sensação de insuficiência levando a pessoa a não encarar a vida como uma missão a ser cumprida. Essa sensação se origina da baixa vital gerada pela depressão endógena. Justine se encontra assim, passa a maior parte do tempo dormindo, não come e não quer tomar banho, às vezes tem crises de choro (é o que vemos no momento 1h09min). A interação com seus familiares é mínima, ela não conversa com eles, apenas é ajudada. Não só um novo planeta, cujo nome é "Melancolia", vem para extinguir raça humana, possivelmente levando as pessoas a pensarem que na vida não há mais nada a ser feito, como também a própria patologia de Justine promove a redução de suas possibilidades de ação. Mas como Frankl (2019b) afirma que o homem pode mudar a si mesmo diante de um sofrimento inevitável, realizando valores de atitude, identificamos que Justine faz essa opção (1h59min52seg). Enquanto o planeta "Melancolia" não concretiza a morte, não colide com a Terra, ela ainda pode realizar valores.

Em Frankl (2019b) alguns valores se dão por ação criadora e há aqueles de vivência. "São os que se realizam, por exemplo, ao acolher o mundo, na entrega à beleza da natureza ou da arte" (FRANKL, 2019b, p. 112). Justine (em12min $12 \mathrm{seg}$ ) se mostra aberta e sensível à beleza da natureza. Neste momento os sintomas de sua depressão ainda não apareceram. Porem mesmo quando esses sintomas a deprimem ela consegue "acolher o mundo", mas o mundo agora é o "Melancolia", cuja ela está totalmente despida diante de sua luz azulada (1h23seg). A cena propõe uma conexão entra a beleza do corpo e a beleza da natureza. Depois desse momento os sintomas depressivos de Justine passam a se esvair um por um.

No decorrer da tragédia (1h58min) Justine enfrenta a depressão e o "Melancolia", quebrando todo "aço", que é sua patologia e o distanciamento do outro que essa promovia, protege sua família e responde a situação de forma bela, segurando a mão de uma criança em seu momento mais trágico (2h01min39seg). 
Para uma pessoa que apenas ficava em seu quarto dormindo e chorando, sem forças até para tomar banho, para quem a vida não tinha mais nem cor nem gosto (1h13min), Justine está de pé, e de forma responsável escolhe acolher seu sobrinho quando ele demonstrava precisar. Aquela que não conseguia se levantar está no meio da mata (1h59min52seg) colhendo matéria prima da bela natureza para proteger seu sobrinho da tragédia. Por ela estar realizando valores, Justine, revela quem realmente é, com isso se entende que ela está escutando sua consciência. Segundo Frankl (2019b) ela está realizando valor de atitude, pois decide mudar a si mesmo diante de sua depressão e de uma situação inescapável e irreversível que é o fim do mundo, que ocorrera na sequência.

A tia "quebra-aço" entra em ação no último instante (1h59min52seg) para salvar o sobrinho, convoca-o a realizar valores como explica Frankl (2019b): de vivência, pois ambos estão manifestando o forte laço afetivo que há entre eles, de tia e sobrinho, de família; é de criação, pois estão criando algo com as próprias mãos para "se protegerem" e protegerem Claire.

Justine (em 1 h58min) revela quem realmente é, o que tem de único e irrepetível nela nos momentos finais da Terra, e isso vem dessa dimensão que está para além do biológico e do psíquico. Mesmo naquele momento trágico valia a pena viver com o seu sobrinho, ela disse "sim a vida apesar de tudo", e chama Leo para dizer sim também, e viver com sentido até o último instante.

Tudo indicava que Justine iria se entregar a depressão endógena, e consequentemente a morte $(1 \mathrm{~h} 31 \mathrm{~min}) .0$ planeta Terra seria instinto e a personagem tem tudo o que precisa para desistir, esperar a morte ou se matar. Mas quem toma essa decisão é outro personagem que não demonstrou em nenhum momento motivo para tal.

John (1h46min) vai por outra via. Mesmo tendo muitos recursos materiais, família, talento e se demonstrando ativo no que fazia, opta pelo suicídio enquanto o planeta "Melancolia" se aproximava. Só enquanto tudo estava de acordo com os cálculos da ciência (1h29min) John estava dizendo sim a vida e a as relações com a sua família.

0 fechar-se em si mesmo, ou o focar em apenas um aspecto de algo que é múltiplo seria o fechamento das possibilidades de realizar Revista Páginas de Filosofia, v. 10, n. 1, p.51-72, jan.-jun. 2021 
valores, seria o adoecimento, o feio. E é o que faz John em 37 min 57 s, aqui não é a patologia de Justine que se destaca, mas sim a escolha do personagem por destacar o preço da festa para ele ao invés de tentar ajudar quem está diante dele precisando. John começa a mostrar aqui sua forma de adoecimento, de fechamento.

Em 1h24min John aparece se divertindo com seu filho, ensinando algumas coisas sobre a observação dos astros e demonstrando como se usa algumas tecnologias de observação. Ele promete a sua esposa que os cálculos dos cientistas estão certos e que o "Melancolia" não iria colidir com a Terra. Aqui John está realizando valores de vivência, experienciando a boa relação com sua mulher e seu filho, uma significativa melhora da sua cunhada e aproveitando todas as suas aquisições materiais que lhe davam certo luxo. Porém John não disse sim à vida mesmo apesar de tudo, como afirma Frankl (2009). O valor que estava acima de todos os valores na vida de John era a "certeza científica" - ao mesmo tempo em que ele enaltece a "certeza cientifica" em sua vida ele a transforma numa forma reducionista de encará-la. Quando sua certeza falha (1h41min), John não encontra mais sentido nesse valor em que se apoiava é cai no vazio existencial, optando pelo suicídio. Ele prometeu o impossível para Claire e deixou de fazer o possível, de realizar valores enquanto houvesse vida.

Já Justine sabendo que iria morrer, e que seus familiares também iriam, decide o quanto antes realizar os valores de vivência e criação com que ama ( $1 \mathrm{~h} 59 \mathrm{~min} 52 \mathrm{seg}$ ). E tudo foi possível, pois ela mudou a si mesma, realizou também valores de atitude.

Quando se combate a morte como uma inimiga, ou nos fazemos de cegos diante dela, vivendo como se ela não existisse, se apegando somente ao material, deixamos para depois o que deve ser feito naquele momento. Quando a tragédia é evidente a pessoa não consegue ver um sentido a qual ela possa se agarrar. John nos mostra que uma das possíveis escolha de quem ignora a morte durante a vida, diante do trágico, da morte, é justamente acabar com a própria vida perante a morte ou o sofrimento. Já Justine nos mostra o contrário. Ela morreu com dignidade e John perde a dignidade diante da morte. "E naquele dia todos morreram". 


\section{CONSIDERAÇões FinAIS}

Através deste trabalho vimos à relação dos conceitos da Logoterapia e Análise Existencial de Viktor Frankl como sentido e valores e a possibilidades de realização desses no trágico. Considerando também o vazio existencial, a depressão e o suicídio, que tanto assola o ser humano nos dias de hoje. Mas vimos que através da abertura às possibilidades, e a mudança de si perante o sofrimento, e a criação de algo e a vivência do amor, são forma de ver o belo na vida, de enfrentar o trágico, e desfrutar de uma vida com sentido e beleza diante da dor e do sofrimento. Já a beleza não só realça como também revela valores e sentido, ao lançar uma luz de possibilidades no que está para ser encerrado como nos mostra o filme na colisão dos planetas. Vimos também que a realização de valores na busca do sentido da vida são formas de beleza e arte mesmo diante do trágico.

Vimos também à relação entre depressão endógena e melancolia. Da primeira a pessoa não escapar, assim como ela não escolher quando os sintomas vão desencadear. Foi assim com Justine cujos sintomas se manifestaram em plena festa de casamento. Já a segunda, é consequência da primeira, pode ser encarada e superada e a personagem nos da um belo exemplo com relação a isso também.

As decisões dos personagens, Justine e John, nos mostram que o homem é livre para escolher até mesmo diante de uma situação sem saída. Porém John não faz uma escolha responsável, pois decide "sair de cena" quando a sua família mais precisava. Já Justine, mesmo com sua depressão endógena, patologia perante a qual não teve escolha, consegue se erguer, sair de um estado de melancolia e cuidar de seu sobrinho e de sua irmã. Justine demonstra fazer isso através dos valores de vivência com a natureza, a arte e os outros, que a amavam, criando formas de se proteger e também mudando a sua atitude perante todo o sofrimento que vivia.

Dizer não a morte não leva a pessoa a dizer sim a vida e dizer sim ao fato de que a vida tem um fim leva pessoa o quanto antes realizar valores e encontra sentido.

A beleza da relação com o outro tem sentido e o sentido da vida é belo mesmo diante da tragédia, que não representa fim da possibili- 
dade de a pessoa optar por uma vida digna. Como nos ensina o Frankl enquanto há vida, ainda há a opção de mudar a si mesmo, de dizer sim a vida até o último instante

\section{REFERÊNCIAS}

AQUino, T. A. A; ALVES, A. C. D; AGUiAR, A. A; \& REFOSCO, R. F. O. Sentido da Vida e Conceito de Morte em Estudantes Universitários: Um Estudo Correlacional. Interação Psicol. 2010a. 14(2), 233-243 p.

AQUinO, T. A. A; SERAFIM, T. D. B; SILVA, H. D. M; BARBOSA, E. L; CIRNE, E. A; \& FERREIRA, F. R; et al. Visões de morte, ansiedade e sentido da vida: Um estudo correlacional. Psicologia Argumento, 2010b. 28(63), 289-302 p.

BARDIN, Laurence. Análise de conteúdo. São Paulo: Edições 70, 2011. 279 p.

FRANKL, Viktor Emil. Em busca de sentido: um psicólogo no campo de concentração. 28. ed. Petrópolis: Editora Vozes, 2009. 186 p.

FRANKL, Viktor Emil. 0 sofrimento humano: fundamentos antropológicos da psicoterapia. São Paulo: É Realizações, 2019a. 368 p.

FRANKL, Viktor Emil. Psicoterapia e sentido da vida. São Paulo: Quadrante, 2019b. $423 \mathrm{p}$.

HAN, Byung-Chul. A salvação do belo. Petrópolis: Editora Vozes, 2019. 126 p.

SARAMAGO, José. As intermitências da morte. São Paulo: Companhia das Letras, 2005. 207 p.

SCRUTON, Roger. Beleza. 5. ed. São Paulo: É Realizações, 2013. 231 p.

Revista Páginas de Filosofia, v. 10, n. 1, p.51-72, jan.-jun. 2021 